\title{
De señales a palabras notas sobre la comunicación en el Discurso sobre la desigualdad de Jean-Jacques Rousseau
}

\author{
Pablo Fucé \\ Instituto de Profesores "Artigas" \\ Montevideo
}

No sin esfuerzo hemos llegado a ser tan desgraciados Jean-Jacques Rousseau

\begin{abstract}
Resumen
Mucho se ha escrito sobre la obra de Jean-Jacques Rousseau pero aún resta desentrañar algunos contenidos de su formulación teórica con miras a la comprensión de su múltiple influencia en la construcción histórica del mundo contemporáneo. Esto bien puede advertirse en su imagen modélica de los modos de expresión del hombre natural y su tránsito hacia el lenguaje verbal y escrito, base del ejercicio político que pone fin al estado de naturaleza y da inicio a la formación de la sociedad civil y la comitiva de vicios y virtudes de toda su cultura.

Palabras clave: Estado de naturaleza - Hombre natural - Comunicación - Sociedad civil - Lenguaje
\end{abstract}

\begin{abstract}
Much has been written about the work of Jean-Jacques Rousseau, but we still do not know some content of his theoretical formulation with a view to understanding of its multiple influences on the historical construction of the contemporary world. This it can be seen in its exemplary image of modes of expression of the natural man and its transit to the verbal and written language, base of the political exercise which puts end to the state of nature and initiates the formation of civil society and culture.
\end{abstract} Key words: State of nature - Natural man - Communication - Language - Civil society

En el Discurso sobre el origen y los fundamentos de la desigualdad entre los hombres (1754), Rousseau construye un modelo político de la humanidad en el que gestos y palabras dichas y escritas ocupan un lugar destacado aunque poco frecuentado por la historiografía. ${ }^{1}$

1 ROUSSEAU, Jean-Jacques, Discours sur l'origine, et les fondements de l'inégalité parmi les

FUCÉ, Pablo, "De señales a palabras. Notas sobre la comunicación en el Discurso sobre la desigualdad de Jean-Jacques Rousseau ”, en Avances del Cesor, Año IX, $\mathrm{N}^{\circ}$ 9, 2012, pp. 163-174. 
En los arquetipos expuestos del hombre natural y el súbdito dieciochesco el filósofo traza los cambios y constantes que mantienen estos medios de expresión así como las relaciones con el contexto en que se desarrollan.

Teniendo en cuenta que Rousseau consideraba a símbolos y significados culturales modos de legitimación del orden establecido propongo que el examen crítico de la comunicación realizado en esta obra permitiría conocer al Yo del filósofo la trama de sentido del lenguaje dominante en la comunidad; un campo nuevo de análisis del naciente sujeto liberal pero no menos político que el de las acciones estrictamente de gobierno.

\section{Gestos y exclamaciones: vestigios de una lengua natural}

En la primera parte del Discurso Rousseau presenta el hombre natural compuesto de sensación y pensamiento potencial, viviendo cada instante los diversos estímulos provenientes del exterior. ${ }^{2}$

En ese tiempo sin principio del estado de naturaleza el primer conocimiento de la humanidad no fue otro que el de su fragilidad corporal, tanto ofensiva como defensiva. Dispersos en un escenario para el que carecían de ideas previas, hombres y mujeres suplían la falta de un instinto propio capaz de anticiparles el peligro o prepararlos para enfrentar mejor la hostilidad del medio con el sentido de la vista, oído y olfato muy desarrollados, y el tacto y gusto extremadamente rudos. Su capacidad de ver con detalle les permitía imitar selectivamente las conductas animales exitosas hasta reproducirlas con el propósito de satisfacer las necesidades de alimentación y resguardo. ${ }^{3}$

hommes, Garnier-Flammarion, Paris, 1992. Acerca del momento intelectual y personal en que se produce el texto véase: TROUSSON, Raymond, Jean-Jacques Rousseau. Gracia y desgracia de una conciencia, Alianza, Madrid, 1995. LABROUSSE, Roger, Rousseau y su tiempo, Editorial Yerba Buena, La Plata, 1945. CLARETIE, Leo, Historia de la literatura francesa, editorial Americalee, Buenos Aires, 1945. HAZARD, Paul, La crisis de la conciencia europea (1680-1715), Alianza, Madrid, 1988. HAZARD, Paul, El pensamiento europeo en el siglo XVIII, Revista de Occidente, Madrid, 1946.

2 Sobre esta cuestión: CASSIRER, Ernst, Le problème Jean-Jacques Rousseau, Hachette, Paris, 1987. CASSIRER, Ernst, La philosophie des Lumières, Fayard, Paris, 1966. GRIMSLEY, Ronald, La filosofía de Rousseau, Alianza, Madrid, 1988. DERRIDA, Jacques, De la gramatologgie, Les éditions de Minuit, Paris, 1967.

3 Apoyándose en deducciones personales, apuntes literarios acerca de los pueblos de la antigüedad y obras contemporáneas de historia natural y de viajeros, Rousseau propone, desde un punto de vista orgánico, la existencia de un modelo espartano en el que la ley natural premiaba con la vida el desarrollo de las destrezas físicas favoreciendo así la continuidad de los más fuertes en una lucha solitaria, desigual y permanente por la sobrevivencia. Sin embargo, y como es sabido, el ensayo no sostiene la preeminencia de lo físico sobre lo psíquico y mucho menos la desigualdad de razas. Por el contrario, Rousseau plantea la igualdad natural de los hombres cuestionando las visiones defensoras de los privilegios de sectores nobiliarios y sacerdotales. 
Para dilucidar las potencialidades psíquicas de la especie Rousseau adopta un enfoque "metafísico" en el que relaciona la interioridad del sujeto con las diversas circunstancias del entorno. Formula para ello la alternancia de dos impresiones básicas: el miedo (asociado al displacer), y la alegría (asociada a la satisfacción). Incapaz de vincular racionalmente los hechos entre sí, y menos todavía de entender sus causas y procesos, la vida humana era cognitivamente limitada y emocionalmente intensa y retraída.

En su retrato del hombre original deseo y temor se transforman en principios anímicos activadores del razonamiento. Al comienzo, apunta, fueron operaciones intelectuales muy sencillas (el "amor de si"), las que aseguraron la autoconservación y rechazo a objetos y situaciones desagradables. A este proceso siguió otro que, en cierto modo, es comparable a un ciclo de inversión: necesidades primero (hambre, sueño, sexo), luego pasiones (deseos de gozo y apropiación y temor a perder o no alcanzar lo deseado), y finalmente desarrollo de la razón (entendimiento), que vuelve a estimular el progreso de las pasiones. ${ }^{4}$

Sin comunidad ni signos instituidos de la lengua en la condición original el hombre desconocía la abstracción así como conceptos y categorías intelectuales. ${ }^{5}$ Las señales intercambiadas eran por entero dependientes de las facultades sensoriales e innatas de la especie así como del contexto en que se producía la co-presencia visible de emisores y receptores. ${ }^{6}$ Imaginémoslo pues, emitiendo determinados sonidos y ejecutando movimientos de manos, brazos, piernas, cabeza y tronco, suficientes para informar a otros, sin ambigüedad, de las pocas, inmediatas y limitadas necesidades del individuo. De acuerdo con Rousseau se trataba de una lengua silenciosa y de difícil estudio para el filósofo, anterior a la razón y

4 Según Rousseau, en ese estado las necesidades físicas eran pocas y básicas y el impulso a las pasiones lo despertaba la naturaleza, compasión e ignorancia atemperaban los enfrentamientos. Asimismo impedían la formación de nociones de vicio o de virtud. Nada dejaba huellas perdurables ni en el cuerpo ni en la mente natural.

5 Sobre lenguaje, gesto e historia: DAVIS, Flora, La comunicación no verbal, Alianza, Madrid, 2008. BURKE, Peter, Formas de historia cultural, Alianza, Madrid, 2000. BREMMER, Jan; ROODENBURG, Herman (ed.), A Cultural History of Gesture. Ithaca, New York, Cornell University Press, 1992 (1991). DUCROT, Oswald; TODOROV y Tzvetan, Diccionario enciclopédico de las ciencias del lenguaje, Siglo veintiuno editores, Buenos Aires, 1975 (1972). REBEL, Günther, El lenguaje corporal, Edaf, Madrid, 2002. ECO, Umberto, Signo, editorial Labor, Barcelona, 1988. HALL, Edward, The hidden dimension, Anchor Books, New York, 1969. LEWANDOWSKI, Theodor, Diccionario de Lingüística, Cátedra, Madrid, 1995. GREIMAS, Algirdas J.; COURTÉS, Joseph, Semiótica. Diccionario razonado de la teoría del lenguaje, Gredos, Madrid, 1991 (1986), T. I y II. JAKOBSON, Roman Ensayos de lingüística general, Barcelona, Seix-Barral, 1975. MAUSS, Marcel, Sociología y Antropología, Tecnos, Madrid, 1979 (1936). LEACH, Edmund, Cultura y comunicación. La lógica de la conexión de los símbolos, Siglo veintiuno editores, Madrid, 1981 (1976).

6 Sobre las interpretaciones del gesto en la cultura europea de la época: KENDON, Adam, Gesture. Visible Action as Utterance, Cambridge University Press, Cambridge, 2005, pp. 17-42. 
al (re)conocimiento del Yo. ${ }^{7}$ Sus mensajes decían poco y preferían el sentido de la vista. Incambiable con el tiempo, ni se extendía ni menguaba y permanecía sin alteración de calidad o número. Sus marcas originales eran la inocencia y el servicio a la autosatisfacción.

En esta condición primitiva las señales visuales y auditivas fueron el primer "grito de la naturaleza" universal, alejado de la historia, la cultura y la política. Increadas por el hombre y eficaces para un mundo sin ideas sólo estuvieron asentadas en la necesidad del comercio de las demandas orgánicas. Tanto por su origen natural, como por su uso y codificación ("icónica" podríamos llamarle), esta forma de comunicación tornaba impracticable cualquier intento de persuasión y de engaño. ${ }^{8}$

Según Rousseau, fueron un medio ligado a la realidad pre-social de la vida humana, cuando cada individuo se mantenía en completa e inseparable unidad entre ser y parecer y sólo se obedecía a si mismo. No fueron, por tanto, gestos ni exclamaciones las que dieron lugar a la fantasía e imaginación, la reflexión y el acuerdo. En pocas palabras, las ciencias y las artes, asociadas desde el Discurso anterior a la dominación política, no estuvieron ni pudieron encontrarse en los gestos y voces del estado natural.

Empero, este modo de expresión ancestral no ha aparecido en el hombre civilizado ni tampoco ha desaparecido, y aquí radica su relevancia política. Del texto se desprende que gestos, posturas y voces ejecutadas por fuera del artificio de la civilidad nobiliaria y de su contracara plebeya, la gesticulación, son la prueba de la existencia de un hombre natural aún reconocible bajo los signos y símbolos dominantes que ha impuesto la política absolutista para clasificar y mantener la desigualdad de estados y condiciones.

La conclusión política del texto asombra a muchos de sus lectores quienes, como Voltaire, comprenden sin ambages los contenidos del mensaje. ${ }^{9}$ El primero: los prejuicios imperantes en los sectores pudientes acerca del mundo plebeyo son, al igual que el comportamiento de los últimos, producto de la sociedad y la política nobiliaria. Sin ambas serían otros o simplemente no serían. En segundo lugar, la monarquía y sus fastos son, contrariamente a lo que propagan sus defensores, enemigos de la concordia en tanto sostienen y multiplican el lenguaje de la subordinación del hombre natural. ${ }^{10}$

7 Ese sujeto interior es "fijo e inmóvil, punto de referencia y medida valorativa de las acciones del individuo". HARTLE, Ann, El sujeto moderno en las Confesiones de Rousseau, Fondo de Cultura Económica, México, 1989 (1983), p. 19.

8 Tomo y adapto los conceptos de origen, uso y codificación de: VERON, Eliseo, PRIETO, Luis, EKMAN, Paul, FRIESEN, Wallace, SLUZKI, Carlos y MASOTTA, Oscar, Lenguaje y comunicación social, Nueva Visión, Buenos Aires, 1971, p. 57 y ss.

9 Véase la carta de Voltaire a Rousseau de 30/8/1755 y la respuesta de éste en ROUSSEAU, Jean-Jacques, Discours sur l'origine, et les fondements de l'inégalité parmi les hommes, GarnierFlammarion, Paris, 1992, p. 259 y ss.

10 NAGLE, Jean, La civilisation du cœur. Histoire du sentiment politique en France du XIIe au XIXe siècle, Paris, Fayard, 1998, p. 329 y ss. 
Por último, la idolatría a la razón y la palabra son para Rousseau errores tan graves como el hecho de aceptar la marcha del progreso a lo largo de la historia, precisamente uno de los puntos, junto al de la potencia del Estado, que más importaba a buena parte del reformismo ilustrado. ${ }^{11}$ El hombre, para Rousseau, carga ocultamente con el dolor de la pérdida de la simplicidad, igualdad y espontaneidad de la lengua original, latente en cada expresión corporal y sonora. Recuperarlas para el ciudadano moderno exige, por tanto, un acto de voluntad política que conduzca la conciencia más allá de la palabra. Es decir, hacia una transformación profunda del individuo y de la comunicación.

Sólo por la fuerza de las condiciones externas el hombre se ha vuelto sociable y ha adquirido un modo de ser determinado, sostiene el filósofo. ${ }^{12}$ En su afán por impugnar los beneficios de la impronta civilizatoria en todos los órdenes de la vida humana, Rousseau ideó un hombre original aislado de sus congéneres, sin ideas, inteligencia, interés por los otros y felicidad. Es en este sentido, y a diferencia de la mayoría de sus predecesores y contemporáneos, que la lengua natural de Rousseau hizo de la especie un completo y verdadero animal humano.

Únicamente luego de ser despojada del lenguaje del súbdito la humanidad podría abandonar la prehistoria y constituir políticamente su interior con otras señales, voces y palabras escritas. Fue en este punto, nada menor, que sus ideas también concurrieron a refutar los fundamentos teológicos y políticos del Antiguo Régimen y sus ecos reverberaron en los procesos revolucionarios posteriores..$^{13}$

\section{La oralidad: una convención emocional encarnada}

Habiendo situado la diferencia entre el hombre y las demás especies en la facultad del primero de elegir Rousseau afirma que el espíritu pronto "deprava los sentidos" en el estado de naturaleza. Anuncia de esta manera al lector el pasaje inmediato a un relato secular sobre el alejamiento del hombre de su condición original, hecho que denomina la primera gran "revolución".

11 POMEAU, René, La Europa de las Luces. Cosmopolitismo y unidad europea en el siglo XVIII, Fondo de Cultura Económica, México, 1988, p. 252 y ss. Acerca del progreso: BURY, John, La idea de progreso, Alianza, Madrid, 1971.

12 La idea moderna según la cual puede haber contraposición entre los intereses del individuo y los de la comunidad ha sido revisada muy frecuentemente desde entonces. Una síntesis y reflexión sobre el particular se encuentra en: CORTINA, Adela, Alianza y Contrato. Política, ética y religión, Trotta, Madrid, 2001. También: KYMLICKA, Will, Filosofía política contemporánea, Ariel, Barcelona, 1995.

13 Véase: DARNTON, Robert, La gran matanza de gatos y otros episodios en la historia de la cultura francesa, Fondo de Cultura Económica de México, México, D.F., 1987. FARGE, Arlette, Subversive Words. Public Opinion in Eighteenth-Century France, Pennsylvania, The Pennsylvania State University Press, 1994 (1992). 
El albedrío es la llave maestra que posibilita a Rousseau descubrir y explicar las características y transformaciones del arquetipo. Retomando planteos de Locke y Condillac, ${ }^{14}$ Rousseau propone que en el hombre natural hubo una oscura tendencia a dar continuidad a las experiencias placenteras y buscar extender la duración de las impresiones que provocaba el contacto físico entre individuos. Gobernados poco a poco por un intenso apego al deseo sensual las acciones del hombre agotaron las posibilidades expresivas del registro gestual. Este deseo se manifiestó exteriormente en el intento de dominio de objetos y sujetos del entorno y en el esfuerzo cada vez más deliberado y consistente de construir una imagen con la cual ser valorado por sus pares.

Pero el medio se convirtió en fin trayéndole su ruina. El hombre pasó a identificarse con su imagen y esta confusión individual trastocó el rumbo de la especie. Fomentadas a diario en incipientes agregaciones humanas, todavía sin vínculo político formal, la belleza, la fuerza y la astucia fueron convirtiéndose en ventajas para atraer y retener a los demás. Con esto se incrementó la inclinación a juzgar como propias las estrategias de un Yo emergente, simulador, relativo y arbitrario. Considerando su nueva realidad como algo permanente el hombre tomó lo ilusorio por verdadero, lo superficial por relevante y lo construido por natural. El personaje sustituyó al actor quien a su vez comenzó a declamar diferentes guiones dentro de la casa, la aldea y en las nuevas tareas que ocupaban sus horas: labrando la tierra y fundiendo metales para armas y herramientas.

A la voluntad de agradar acompañaron los celos y la envidia y a la reputación el menosprecio. La paz del estado natural desapareció fruto de la competencia y las alianzas y rivalidades día a día renovadas; las expectativas de revancha, no menos que las de liberación, fueron depositadas desde entonces en el mañana impidiendo disfrutar el hoy; asimismo, y sin contradicción, el hombre pasó a vivir en el pasado. El recuerdo de los ultrajes los atormentó a todos y desde entonces se puso fin a la niñez de la especie. Victoria y derrota las sintió la especie corriendo en su sangre como nunca antes. En este nuevo estado el hombre obedeció al deseo y pasó ciegamente a creer en él.

Desbordando las necesidades inmediatas de la etapa anterior el hombre creó otras más difíciles de alcanzar. En paralelo al incremento de la memoria y la activación de nuevas actividades cognitivas con el propósito de superar los obstáculos ${ }^{15}$ que se presentaban para obtener placer, los individuos estrecharon los contactos, incrementaron sus fuerzas al unirlas y con ello dieron continuidad y firmeza a los afectos en curso. Por primera vez el hombre llenó de contenido las nociones de inversión e interés, ganancia y pérdida.

El establecimiento de la palabra fue una de las más notables consecuencias de estos

14 ABBAGNANO, Nicolás, Historia de la filosofía, Hora, S. A., Barcelona, 1994 (1956), V. II, p. 369.

15 Véase STAROBINSKI, Jean, Jean-Jacques Rousseau, la transparencia y el obstáculo, Taurus, Madrid, 1983 (1971). 
cambios. Las primeras categorías del pensamiento florecieron con ella aunque aún se mantuvieron sujetas a otros modos de comunicación menos apropiados al ánimo. Fascinado con su imagen y el entorno que le despertaban emociones parecidas o equivalentes a las que le agradaban, el hombre natural agregó a los gestos la palabra. Ésta (re)unío a la especie en el goce tanto como facilitó la expresión del sufrimiento generado por la competencia y la rivalidad. ${ }^{16}$

Los balbuceos del estado original, realizados junto al gesto, se refinaron muy pronto hasta formar lenguas enteras de grupos domésticos y comunidades. Perfeccionadas por el fuego de las pasiones, y las artes que las exteriorizaron, las lenguas habladas facilitaron distinguir la manera de vivir de los sexos patrocinando en los grupos el comienzo del "amor conyugal y el amor paterno"; su constitución no fue ajena a su fin. En ella prevalecieron los giros poéticos inseparables de figuras fáciles de asociar por emisores y receptores a las más impresionantes emociones. Se trató, en suma, de una lengua cuasi musical de voces naturales inarticuladas y de sonidos muy variados que multiplicaron los acentos expresivos asistiendo primero e imponiéndose después, sobre el mundo primitivo y natural de la comunicación no verbal.

En esta lengua de la seducción importaba mucho el ritmo por lo que Rousseau insiste en afirmar que estaba cerca del canto y en ella predominaba casi de continuo la onomatopeya. A diferencia de los gestos naturales la lengua resultó de una convención no declarada formalmente entre los involucrados mas no por esto menos vinculante ni efectiva; contaba con pocos adverbios y palabras abstractas y se componía de sentencias capaces de convencer sin pretender persuadir con argumentos y de enseñar los estados del sujeto sin razonarlos demasiado. Resumiendo, se trataba de la lengua emergente del Yo artificial, todavía en proceso de constitución psíquica.

Rousseau sostiene que en todos los grupos humanos que han incrementado sus necesidades y agregado al apetito la imaginación y fantasía se desarrolló esa lengua sin que esto supusiera que debieran pasar a una etapa de escritura. El filósofo halla rastros de esa lengua cantada en el relato de la Ilíada y llega a dudar que en la época de Homero pudiera conocerse la escritura. La poesía viene, según dice, antes que la prosa; citando a Estrabón afirma que hay un periodo del Hombre en que decir y cantar son casi lo mismo.

Indagando sobre el origen de la vida en común y el último tramo del estado natural, Rousseau concluye que este discurso hablado fue uno de sus mayores inventos por hallarse en la base del esfuerzo por redoblar y extender las impresiones humanas. Mientras placer y dolor eran descubiertos en el gesto, la voz de la tragedia inflamaba el corazón al jugar y acrecentar la imaginación de rapsoda y oyente. Las primeras historias, arengas y leyes no

16 Etapa de "felicidad" que ha sido subrayada en varios trabajos. Véase, por ejemplo, TOUCHARD, Jean, Historia de las ideas políticas, Tecnos, Madrid, 1988, p. 328 y ss. 
escritas tuvieron existencia en el verso y enraízaron con las emociones antes y mejor que con la razón aún dormida.

En un texto recién publicado luego de su muerte pero redactado en la misma fecha que este Discurso y que sirviera de base al mismo, Rousseau apuntó que la palabra pudo ocurrir recién cuando los gestos afirmaron las pasiones del hombre y le condujeron a otro estadio de comunicación. ${ }^{17}$ Acontecido esto, la lengua subordinó todo el proceso del estadio precedente. En las primeras etapas del hombre natural, agrega, más cosas decía una mujer a su amante dibujando gustosamente su sombra que empleando palabras.

En efecto, señala, los pueblos antiguos (es decir, quienes estaban presumiblemente más libres de las ataduras sociales conocidas y con quienes cabe entonces establecer analogías para pensar el hombre natural), expresaban lo más vivo y profundo con signos, no con palabras; lo mostraban, añade, no lo decían ${ }^{18}$. Resulta de este modo que la diferencia entre el sexo y el amor es comparable para el filósofo a la que existe entre el gesto y la palabra, entre el estado presocial y la existencia y reproducción de toda una cultura y sociedad.

En suma, el proceso de constitución de la lengua le resulta a Rousseau histórico, social y tardío, producto de una convención sostenida en el intercambio regular de necesidades y basada en la expansión interna de pasiones autocentradas: "no fue el hambre ni la sed, anotó, sino el amor, el odio, la piedad y la cólera, los que les arrancaron [a la humanidad] las primeras voces". ${ }^{19}$ Desarrollada la imaginación y activado el entendimiento esta etapa puso fin a la de "argumentar a los ojos" y se convirtió en un momento decisivo de la especie identificado por el filósofo en individuos y grupos en los cuales el signo primitivo ya no es, como era antes, capaz de decirlo todo sin recurrir a la palabra.

\section{El artificio político: oralidad y escritura o las formas de razonar y de mentir}

El ejercicio de elegir para atraer a su figura la atención y estima de sus semejantes fue estructurando en cada individuo lo que Rousseau denomina la conciencia humana de la libertad. Ella no se mantuvo en paz y equilibrio y devino, en cambio, perturbada y hostil. El "amor de si" fue supeditado a las impresiones egoístas del "amor propio". El ascenso de la razón al dominio de la psiquis (el alma en palabras de Rousseau), ocultó la retirada del sentimiento ${ }^{20}$, nutrió la sofisticación retórica, perfeccionó el discernimiento, contribuyó a la

17 ROUSSEAU, Jean-Jacques, Ensayo sobre el origen de las lenguas, Fondo de Cultura Económica de México, México, D.F., 1984, p. 16.

18 Ídem, p. 12.

19 Ídem, p. 18.

20 La sinceridad fue considerada por Rousseau, al igual que en otros de sus contemporáneos, una manifestación del sentimiento natural oprimido por las posturas afectadas de la vida cortesana. Acerca 
formación del sujeto político y provocó el ingresó de la especie en la Historia propiamente dicha.

Una vez más Rousseau recurre a pares de opuestos para orientar el análisis hacia la crítica de la realidad socio política señorial en la que encontraba la perpetuación de formas y contenidos culturales del pretérito. Y en esta operación analítica el filósofo va creando nuevos mitos que vienen a sustituir a los más extendidos en el viejo orden político y social. ${ }^{21}$ Lo natural, siempre positivo para él, es la base estable contra la que se erige toda la cultura dominante siguiendo un desarrollo de complejidad creciente a la vez que deducido, relativo, parcial y dependiente..$^{22}$

$\mathrm{El}$ arte de comunicar los pensamientos, como le llama Rousseau, partió de la etapa anterior de la voz y la complejizó. A cada objeto, sin distinción inicial de género o especie, el hombre había asignado un nombre particular con el que formó por mnemotecnia un extenso diccionario. De la mano de la observación atenta y la diferenciación racional creciente fueron inventándose y reproduciendo en las pequeñas agrupaciones de individuos los términos preferidos hasta fijar las primeras clasificaciones de uso corriente. Casi sin notarlo vinieron las proposiciones y con ellas la formulación de ideas generales. La voz emocional estimuló procesos intelectuales de abstracción y generalización no solo artística, sino filosófica y pre-científica.

Un asunto central en el Discurso es la afirmación definitiva de la propiedad y con ella el pasaje a la comunicación civilizada, tema clave al filósofo que investiga su dimensión política. ${ }^{23}$ Reparemos un instante en la descripción que presenta.

A juicio de Rousseau el fundador de la sociedad civil recurrió primero al gesto (cercó el terreno), e inmediatamente proclamó al conjunto reunido de sus semejantes: Ceci est à moi. La apropiación y la inmediata serie de expropiaciones que le siguieron derivan así, fundamentalmente, de la existencia de códigos de comunicación preestablecidos que le dieron sentido y significado (político) al hecho económico. La lengua emocional facultó al hombre a distinguir entre lo propio y lo ajeno. El uso deliberado de signos y símbolos, mucho más que el de la fuerza física, hizo posible al poderoso la apropiación de los frutos (que eran

del sentimentalismo en la Francia de Rousseau (1700-1789), véase: REDDY, William M., The Navigation of Feeling. A framework for the History of Emotions, New York, Cambridge University Press, p. 141 y ss.

21 JAUSS, Hans Robert, Las transformaciones de lo moderno. Estudio sobre las etapas de la modernidad estética, La balsa de la Medusa - Visor, 1995, p. 25 y ss. HORKHEIMER, Max y ADORNO, Theodor, Dialéctica de la Ilustración. Fragmentos filosóficos, Trotta, 2001. MARCUSE, Herbert, "Sobre el carácter afirmativo de la cultura" en Cultura y Sociedad, Sur, 1969.

22 HÖFFDING, Harald, Rousseau, Revista de Occidente, Madrid, 1931, p. 124.

23 ROUSSEAU, Jean-Jacques, Discours sur l'origine, et les fondements de l'inégalité parmi les hommes, Garnier-Flammarion, Paris, 1992, p. 222. 
de todos) como así de la tierra (que no era de nadie), apunta Rousseau; la molicie de unos pocos y la sobrecarga de tareas en muchos fue una de sus consecuencias en el largo plazo.

De igual forma, con el establecimiento del pacto "inicuo" planeado por los fuertes para terminar con la guerra extendida a fines del estado natural Rousseau reafirma en el texto el carácter político de la comunicación humana convertida desde entonces en otro modo de luchar con(tra) el poder y la autoridad. ${ }^{24}$ El "unámonos" de los poderosos fue una voz que ordenó y trajo consigo, para emisores y receptores, la formación de la sociedad civil, el surgimiento del Estado y las primeras formas de gobierno. ${ }^{25}$

El "estado de guerra" fue reemplazado por una paz relativa e inestable, consecuencia de la institución de una fuerza legítima pero antinatural acompanada de los primeros reglamentos escritos de justicia. El consentimiento dado por los pobres y débiles fue una extensión tanto del vivir fuera de si como del poder de seducción que acompañaba el discurso hablado. También del nuevo culto a la palabra propagado por los fuertes quienes desde entonces la tomaron salvadora cuando antes apropiada para dividir y enfrentar.

En términos de Rousseau, hubo una acción específica que confirmó la aquiescencia de los débiles: "todos corrieron a los hierros creyendo asegurar su libertad". ${ }^{26}$ El uso deliberado de signos y símbolos, mucho más que el de la fuerza física, hizo posible a los magnates obtener obediencia de sus semejantes, conservarla y hacer de ella, poco después, un poder arbitrario.

En los dos casos mencionados, el hombre ficticio de Rousseau, usurpador innominado e ignominioso, hizo uso del lenguaje verbal para fingir sus propósitos de dominación e instituir, casi a la vez con auxilio de la ley escrita y sus cultores, un orden político estatal tan contrario a la naturaleza como beneficioso para consagrar tres pares antagónicos fundamentales en la nueva era política que se iniciaba: el de fuerte/débil, rico/pobre (ambas situaciones provenientes del periodo inmediatamente anterior), y el jurídico político de amo y esclavo.

Oralidad y escritura son para el filósofo elaborados dispositivos de conservación de un estado de cosas en el que los hombres de todas las condiciones se ven forzados a acariciarse mientras traman destruirse mutuamente y en el que, agrega, desde su nacimiento son enemigos por deber y pérfidos por interés.

El antiguo substrato de deberes y obligaciones mutuas favorables a la desigualdad - ya asentado en costumbres e interpretado con palabras dichas y ahora escritas - fue valorado por las élites dominantes y utilizado para dar forma y contenido a la figura política que sustituyó al hombre natural: el súbdito del régimen absolutista. ${ }^{27}$

24 CHATELET, François y DUHAMEL, Olivier; PISIER-KOUCHNER, Evelyne, Historia del pensamiento político, Tecnos, Madrid, 1987 (1982), p. 74.

25 BOBBIO, Norberto, Estado, gobierno y sociedad, Fondo de Cultura Económica, México, 1994.

26 El subrayado me pertenece.

27 El arquetipo del súbdito es señalado a lo largo del texto lleno de "amor propio", dedicando sus horas a leer en aromas, colores, sonidos y grafías mensajes de alianza o enemistad entre parientes, 
Una vez corrido el "tupido velo del error", Rousseau sólo observa el "horror" que acompaña las rutinas de la corte (secular y religiosa) y confunde el honor con la virtud, la razón con la sabiduría y el placer con la felicidad. ${ }^{28} \mathrm{El}$ artificio político es una máquina de muerte que conmueve el corazón y perturba el entendimiento. No hay individuo que a la vista del filósofo diga la verdad. Por el contrario, el ardor por hablar de uno mismo, apunta Rousseau, revela que hasta los vicios deben ser fingidos por quien busca la opinión de los demás y que conquistadores y filósofos están más emparentados de lo que a menudo estarían dispuestos a reconocer.

\section{El Yo frente a los desafíos de la (nueva) comunicación política}

El Discurso es una pieza ágil, compleja, sugestiva y contradictoria. Como es sabido, su influencia ha sido enorme en la filosofía, la política, la historia, la antropología y la lingüística, entre otras disciplinas. Corriendo el riesgo de simplificar, los siguientes serían algunos problemas emergentes del análisis de la dimensión política de la comunicación que descubre Rousseau a sus lectores.

Por un lado, en el ensayo se percibe la firme creencia de Rousseau en la posibilidad de una razón filosófica liberadora capaz de (re)encontrar en la historia individual y colectiva a la naturaleza y elevar así las condiciones de la comunicación política del género humano. Sin embargo, esto supone la capacidad del Yo de revisar el pasado como un observador distanciado y cambiar a voluntad los fines y el sentido de la vida formados en esa misma trágica y extensa peripecia colectiva del mal.

Por otra parte, el estudio de la dimensión política de la comunicación conduce al filósofo a enfrentar el problema de la legitímidad de las reglas del juego político y de la historia gestual, oral y escrita que las explica y sostiene. El Discurso no proporciona pistas acerca de cómo adoptar un nuevo orden basado en modos específicos de comunicación verdaderamente afínes a la defensa de los derechos del naciente ciudadano y abre, en cambio, nuevas interrogantes: ¿no puede un Yo "virtuoso", "sabio" y "feliz”, como quiere Rousseau, preferir expresarse con señales naturales, con la oralidad poética del sentimiento e incluso con la

amigos y vecinos, aldeas y comunidades. Su desarrollo cognitivo se completa al ser capaz de formulaciones intelectuales elevadas que comprenden, entre otras manifestaciones, el uso del número, las palabras abstractas, los aoristos y todos los tiempos verbales. En este sentido, cabe añadir que se ha dicho con razón que el pensamiento de la Ilustración construyó "figuras de la perversión y de la coincidencia, del despotismo y de la felicidad, incesantemente renovadas". CHÂTELET, François y MAIRET, Gérard (editores.), Historia de las ideologías, Akal, Madrid, 1989 (1978), p. 449.

28 Acerca de las rutinas nobiliarias relativas a la gestualidad y la voz: BOUZA, Fernando, Palabra e imagen en la corte. Cultura oral y visual en el Siglo de Oro, Abada editores, Madrid, 2003. APOSTOLIDĖS, Jean-Marie, Le roi-machine. Spectacle et politique au temps de Louis XIV, Les éditions de Minuit, Paris, 1981. 
voz racional y el texto escrito de la tradición filosófica precedente? ¿O debe el ciudadano, en su oposición al súbdito, comunicarse únicamente de la manera que el político-filósofo y filósofo-político juzgue liberada del comportamiento indolente del salvaje, las ataduras de la pasión y el artificio de la palabra hablada y escrita por hombres infames? Es cierto que en sus Confesiones, por no hablar del Contrato Social y de Emilio, ambos escritos en paralelo y publicados en 1762, propondrán algunas respuestas. También es cierto que guardarán silencio sobre esto.

En tercer lugar, la solución al problema del desdoblamiento y desequilibrio interior del Yo que traza en el Discurso (sintetizado en los pares amor de si/amor propio, ser/parecer), y liga a la imperfección secular de los hombres día y noche crispados por conflictos cuyo origen es la desigualdad política y económica (que resume con los pares antagónicos de fuerte/débil, rico/pobre y amo/esclavo), tampoco está en la sociedad, pues ésta es concebida desde su génesis misma como agregación anti natural y forzada de individuos que devienen egoístas y corruptos.

En lo que respecta a las ciencias y las artes tampoco cabe esperar una salida positiva. Menos despóticas pero más poderosas, como había escrito en el Discurso sobre ellas, lejos de redimir a los hombres no son otra cosa que guirlandes de fleurs sur les chaînes de fer dont ils sont chargés. Por paradójico que resulte, y a pesar de todas sus limitaciones, parecería que solo de la lengua natural de los gestos - tan poco conocida y más cerca de la animalidad que las otras - pudiera desprenderse, acaso, una esperanza para recomponer la política. De voces y palabras escritas en cambio, y en la medida que se conciben vehículos de las doctrinas establecidas, no puede aspirarse en principio emancipación alguna.

En el Discurso sobre el origen y los fundamentos de la desigualdad la humanidad no es un dato sino una posibilidad. No era humano el hombre natural ni tampoco la sociedad civil establecida. De ahí que, intentando transformar la realidad, el filósofo abordara críticamente la dimensión política de la comunicación explorando un nuevo campo de indagación liberal que conocería múltiples ramificaciones.

A lo largo del texto Rousseau propone que la verdad está más allá de la lengua, que la palabra es ilusión y la comunicación engaño. Al mismo tiempo, la filosofía política de la Ilustración imponía el desideratum del ciudadano libre de insensatez, superstición e ignorancia. Rousseau cabalgó con su Discurso entre dos épocas: acompañó el proyecto moderno de la Ilustración a la vez que sembró la duda contemporánea sobre su viabilidad y los medios de alcanzarlo.

Recibido: 05/04/2012

Aceptado: 12/06/2012 